\title{
Halibut Liver Oil
}

National Cancer Institute

\section{Source}

National Cancer Institute. Halibut Liver Oil. NCI Thesaurus. Code C107313.

The oil extracted from the liver of Hippoglossus species. Halibut liver oil is taken as a supplement for vitamins A and D. 